\title{
Thyroid peroxidase antibody levels among human immunodeficiency virus infected patients in Kano, North-Western Nigeria
}

\author{
Isah A. Yahaya, ${ }^{1}$ Sherifah U. Sherif, ${ }^{2}$ Kabiru Abdulsalam ${ }^{1}$ \\ ${ }^{1}$ Department of Chemical Pathology and Immunology, Bayero University/Aminu Kano Teaching Hospital, \\ Kano; ${ }^{2}$ Department of Chemical Pathology and Immunology, Aminu Kano Teaching Hospital, Kano, \\ Nigeria
}

\begin{abstract}
Autoimmunity plays a role in the development of thyroid dysfunction in human immunodeficiency virus (HIV) infected patients. This study assessed the serum levels of thyroid peroxidise antibody (TPO-Ab) in relation to the various forms of thyroid dysfunction in HIV patients in Kano. Free tri-iodothyronine $\left(\mathrm{fT}_{3}\right)$, free thyroxine $\left(\mathrm{fT}_{4}\right)$, thyroid stimulating hormone (TSH) and TPO-Ab were measured using Chemiluminescent immunoassay(CLIA) on the serum of 70 HIV sero-positive patients on Highly Active Antiretroviral Therapy (HAART, as Group I), 70 HAART naïve HIV sero-positive patients (Group II) and 70 apparently healthy HIV negative controls (Group III). The prevalence of thyroid dysfunctions were $55.7 \%, 42.9 \%$ and $2.8 \%$ among groups I, II and III respectively. TPO-Ab was elevated in $1(1.43 \%)$ HIV positive patient on HAART, Group I, that also had subclinical hyperthyroidism. Four participants $(5.7 \%)$ among group III were found to have elevated anti-TPO levels. Thyroid dysfunction was more common among HIV-positive than HIV-negative participants. Thyroid dysfunction among HIV patients was mainly non-autoimmune in origin. However, thyroid autoimmunity appears to play a little role in the development of hyperthyroidism in HIV patients.
\end{abstract}

Correspondence: Kabiru Abdulsalam, Department of Chemical Pathology and Immunology, Bayero University/Aminu Kano Teaching Hospital, Kano, Nigeria.

Tel.: +234.8039749586 .

E-mail: kabdussalam.cpat@buk.edu.ng

Key words: human immunodeficiency virus, free thyroxine, free triiodothyronine, thyroid stimulating hormone, thyroid peroxidise antibody.

Contributions: the authors contributed equally.

Conflict of interest: the authors declare no potential conflict of interest.

Funding: none.

Received for publication: 16 May 2018.

Revision received: 9 June 2018.

Accepted for publication: 29 June 2018.

This work is licensed under a Creative Commons Attribution NonCommercial 4.0 License (CC BY-NC 4.0).

CC Copyright I.A. Yahaya et al., 2018

Licensee PAGEPress, Italy

Annals of African Medical Research 2018; 1:15

doi:10.4081/aamr.2018.15

\section{Introduction}

HIV infection and the most advanced stage of HIV infection, known as Acquired Immune Deficiency Syndrome (AIDS) have become one of the most important public health challenges in the world since its discovery in $1981 .^{1}$ The disease is associated with significant morbidity and mortality in patients and constitute a serious burden to the health care system. ${ }^{1}$

According to the joint United Nations program on HIV/AIDS (UNAIDS), the global prevalence rate of HIV in adults was $0.8 \%$ in $2016 .^{2}$ The estimated prevalence of the disease in Sub-Saharan Africa was about $4.8 \%$ while in Nigeria, the estimated prevalence of HIV/AIDS continues to hover around $4 \%$ for the last 12 years. ${ }^{2,3}$ The HIV/AIDS prevalence rate in Kano state was estimated to be about $1.3 \%{ }^{4}$

As a result of the increasing life expectancy of HIV/AIDS patients following the improved access to highly active antiretroviral therapy (HAART), a number of HIV associated endocrinopathies have emerged. These endocrine abnormalities may be encountered either early or during the late stages of HIV infection. ${ }^{5}$

Studies conducted globally, among different patient populations reported increased prevalence of abnormalities of thyroid function tests and thyroid dysfunction in patients with HIV/AIDS. ${ }^{6-10}$. Thyroid dysfunction has also been reported in the form of autoimmune thyroid disease, Graves' disease being the commonest as part of immune reconstitution inflammatory syndrome (IRIS) following the use of HAART. ${ }^{11}$ Others include Hashimoto's thyroiditis and autoimmune hypothyroidism. An increase in the serum levels of thyroxine binding globulin and a slight decrease in the level of reverse $\mathrm{T}_{3}$ were some of the other key abnormalities noted in patients with HIV/AIDS. ${ }^{11}$

Consequently, evaluation of patients for thyroid autoimmunity now constitute an important aspect of the complete thyroid function assessment profile of this group of patients. Some of the parameters used in assessing thyroid autoimmunity include thyroid peroxidise antibody (TPOAb), anti-thyroglobulin (anti-Tg), and thyroid receptor antibodies (TRAbs). ${ }^{12}$

Previous studies on thyroid function abnormalities in HIV/AIDS patients in Nigeria were limited in scope to the routine biochemical parameters of thyroid function i.e thyroid stimulating hormone (TSH) and either total or free thyroid hormones. Hence the role of autoimmunity in thyroid disorders among HIV/AIDS patients was not investigated.

The aim of this study therefore, was to evaluate the serum levels of thyroid peroxidise antibody (TPO-Ab) in relation to the various forms of thyroid dysfunction among HAART-treated HIV/AIDS patients, HAART-naïve HIV/AIDS patients and HIVnegative controls. 


\section{Materials and Methods}

This cross-sectional study was conducted at the HIV Management Centre of Aminu Kano Teaching Hospital (AKTH), Kano. The centre adopts the National Guidelines on HIV/AIDS treatment of adults and children in Nigeria, hence HAART eligibility is based on WHO recommendations. ${ }^{13}$

A total of two hundred and ten participants were sampled and studied. They were made up of 70 HIV sero-positive patients on HAART (Group I), 70 HAART naïve HIV sero-positive patients (Group II) and 70 apparently healthy HIV negative controls (Group III).

Group I study participants were further sub-divided based on their HAART regimen into those on first line HAART (Ia) and those on second line HAART (Ib).

Groups I and II participants were clinically stable HIV seropositive patients between the ages of 18 and 60 years that were either on HAART or were HAART naïve respectively. Age- and sex-matched apparently healthy HIV sero-negative individuals served as controls (group III). Pregnant women and lactating mothers were excluded from the study, patients with acute illnesses, patients with history of thyroid dysfunction prior to diagnosis of HIV, all patients on medications known to affect thyroid function such as Androgens. Furthermore, patients with history of major neck surgery or irradiation and those with any history suggestive of chronic alcohol abuse were excluded. Patients with AIDS-related malignancy, active opportunistic infections, pituitary, hypothalamic, or neurologic diseases were also excluded from the study.

Approval to conduct the study was obtained from the Health Research Ethics Committee of AKTH. Informed written consent was also obtained from each of the participants after verbal explanation on the objectives of the study to them in a language well understood by them. All data collected from the participants were treated with utmost confidentiality.

A single sample of 5 millilitres of whole blood was obtained for the analysis of $\mathrm{fT}_{3}, \mathrm{fT}_{4}, \mathrm{TSH}$ and TPO-Ab. A well-lit room was used for all phlebotomy procedures and tourniquet was applied only when necessary.

The sera obtained after centrifugation of the whole blood were stored at $-20^{\circ} \mathrm{C}$ and were analysed in batches within 3 weeks of collection. Serum levels of TSH, free thyroid hormones and TPO-Ab are stable at this temperature for up to one month. ${ }^{14}$

Quantitative measurements of serum fT3, fT4, TSH and TPO$\mathrm{Ab}$ were done using highly sensitive and specific electrochemiluminescence (ECL) technique on Cobas e411 automated immunology analyser.

\section{Primary outcome measures}

Values of TPO-Ab $<35 \mathrm{IU} / \mathrm{mL}$ were considered as within the reference range while values $>35 \mathrm{IU} / \mathrm{mL}$ were considered elevated. ${ }^{12}$

The reference ranges of $\mathrm{fT}_{3}, \mathrm{fT}_{4}$ and TSH were 3.1-6.8 pmol/L, $12-22 \mathrm{pmol} / \mathrm{L}$ and $0.3-4.2 \mu \mathrm{IU} / \mathrm{mL}$ respectively.

\section{Statistical analysis}

All data collected were entered into Microsoft excel spread sheets, checked for errors and subsequently exported into STATA version 13 (Stata Corp., College Station, Texas, USA). Mean and Standard Deviation (SD) were used to summarize quantitative data. TSH and TPO-Ab being skewed in distribution were summarised using Median and Range. Qualitative data were presented as proportions and percentages. Analysis of variance (ANOVA) test was used to compare the means between groups I, II and III for $\mathrm{fT}_{3}$ and $\mathrm{fT}_{4}$ while Kruskal-Wallis test was employed to analyse nonparametric data from TSH and TPO-Ab.

In all the statistical analyses, 5\% alpha level of significance which corresponds to 0.05 was considered as statistically significant. ${ }^{15}$

\section{Results}

The age distribution of study participants is shown in Table 1 . The mean age of all the participants was $35.4 \pm 8.5$ years, while the corresponding mean age for groups I, II and III were $38.31 \pm 7.86$ years, $34.44 \pm 8.95$ years and $33.31 \pm 7.99$ years respectively.

Table 2 shows the distribution of the study participants by gender. There was slight more females in both groups I and II and more males among group III participants, with male to female ratio of 1:1.1, 1:1.2 and 1.5:1 for groups I, II and III respectively.

Majority of the participants in all the three groups studied were married $58.6 \%, 61.4 \%$ and $68.6 \%$ in groups I, II and III respectively (Table 2) The commonest occupation engaged by participants in both groups I and II were business and the occupations listed as others, while most of the group III participants were civil servants. The occupations termed as others were petty trading, students and the unemployed.

The mean serum $\mathrm{fT}_{3}$ differ among all the studied groups $(\mathrm{P}=0.0000)$. However, there was no statistical difference between the mean $\mathrm{fT}_{4}$ of group I and group II participants $(\mathrm{P}=1.000)$ but a significant difference was observed when both means were compared to the mean $\mathrm{fT}_{4}$ of group III ( $\mathrm{P}$ value $\left.=0.000\right)$. Statistically significant differences were noted in the median TSH $(\mathrm{P}=0.0001)$ and median $\mathrm{TPO}-\mathrm{Ab}(\mathrm{P}=0.0001)$ of the three groups studied (Table 3$)$.

Table 1. Age distribution of participants.

\begin{tabular}{lccc} 
Age group (years) & $\begin{array}{c}\text { Group I } \\
\mathbf{N}(\%)\end{array}$ & $\begin{array}{c}\text { Group II } \\
\mathbf{N}(\%)\end{array}$ & $\begin{array}{c}\text { Group III } \\
\mathbf{N}(\%)\end{array}$ \\
$\leq 20$ & $1(1.4)$ & $2(2.9)$ & $3(4.3)$ \\
$21-30$ & $15(21.4)$ & $24(34.3)$ & $19(27.1)$ \\
\hline $31-40$ & $28(40.0)$ & $28(40.0)$ & $39(55.7)$ \\
$41-50$ & $22(31.4)$ & $13(18.6)$ & $7(10.0)$ \\
\hline $51-60$ & $4(5.7)$ & $3(4.7)$ & $2(2.9)$ \\
Total & $70(100.0)$ & $70(100.0)$ & $70(100.0)$ \\
\hline
\end{tabular}

Table 2. Socio-demographic characteristics of the study participants (tot 70).

\begin{tabular}{llccc}
$\begin{array}{l}\text { Socio- } \\
\text { Demographic } \\
\text { Variables }\end{array}$ & $\begin{array}{l}\text { Characteristic } \\
\text { Sex }\end{array}$ & $\begin{array}{c}\text { Group I } \\
\text { N (\%) }\end{array}$ & $\begin{array}{c}\text { Group II } \\
\text { N (\%) }\end{array}$ & $\begin{array}{c}\text { Group III } \\
\text { N (\%) }\end{array}$ \\
& Male & $34(48.6)$ & $32(45.7)$ & $42(60.0)$ \\
\multirow{4}{*}{ Marital status } & Female & $36(51.4)$ & $38(54.3)$ & $28(40.0)$ \\
& Married & $41(58.6)$ & $43(61.4)$ & $48(68.6)$ \\
& Single & $11(15.7)$ & $8(11.4)$ & $21(30.0)$ \\
& Divorced & $8(11.4)$ & $6(8.6)$ & $0(0.0)$ \\
& Widowed & $10(14.3)$ & $13(18.6)$ & $1(1.4)$ \\
\hline \multirow{2}{*}{ Occupation } & Civil servant & $15(21.4)$ & $6(8.6)$ & $48(68.6)$ \\
& Business & $20(28.6)$ & $31(44.3)$ & $2(2.8)$ \\
& Others & $35(50.0)$ & $33(47.1)$ & $20(28.6)$ \\
\hline
\end{tabular}


The prevalence of thyroid dysfunction among the various groups studied were $55.7 \%, 42.9 \%$ and $2.8 \%$ for groups I, II and III respectively. TPO-Ab was elevated in $1(1.43 \%)$ HIV positive patient on HAART that also had subclinical hyperthyroidism. Four participants (5.7\%) among the control group had elevated TPO-Ab levels but their thyroid function test findings were within reference limits (Table 4).

The median serum TSH for group Ia and group Ib were analysed and the $\mathrm{P}$ value was 0.001 , which shows that the variation among the two groups was statistically significant (Table 5).

Similarly, the mean $\mathrm{ft} 4$ of the group 1a participants was significantly lower than the mean $\mathrm{ft} 4$ of group $1 \mathrm{~b}$. There was no statistical significant difference in the median TPO-Ab levels between groups Ia and $\mathrm{Ib}(\mathrm{P}=1.000$, Table 5).

\section{Discussion and Conclusions}

Age related differences were noted among the participants in this study. The mean age of the HAART treated HIV positive participants in this study was slightly higher than that their counterparts who were HAART naïve, implying that the HAART treated are slightly older. This may be attributed to the positive influence of HAART in increasing the life expectancy of the treated individuals. ${ }^{16}$ However, the highest number of participants in both groups were between the ages of 31-40 years. Similarly, the age group with the highest number of participants among the HIV negative control group was between 31-40 years. This observation is desirable because it shows that the groups were well matched and their results were comparable.

The slight female preponderance among the HIV infected studied groups suggested that the disease was more prevalent in the females compared to their male counterparts in the study area. Studies conducted in Awka (South-East Nigeria) and NassarawaEggon (North-Central Nigeria) reported female preponderance of $68.9 \%$ and $51.5 \%$ respectively. ${ }^{17,18}$ Similarly, other studies conducted outside Nigeria also reported female preponderance. ${ }^{19,20}$

In contrast, Iliyasu and colleagues reported male preponderance of $54.6 \%$ from a study conducted previously in Kano. ${ }^{21}$

Married couples constituted majority of subjects in the studied groups. This is in agreement with the study conducted in Nassarawa-Eggon and this observation may be due to increased awareness of HIV infection, availability of more voluntary counselling and testing (VCT) services and less stigmatization. ${ }^{18}$

There were more widows in the HAART naïve group compared to the HAART treated group. Most of these widows discovered their HIV status after the demise of their spouses, and this probably explains the delay in diagnosis and commencement of HAART treatment in them as some of them were HAART eligible but have not commenced ARTs because they were presenting for the first time to the hospital at recruitment into this study.

This study has demonstrated that the prevalence of overt and subtle thyroid dysfunction were higher among HIV positive participants on HAART than the HAART naïve group.

However, this prevalence was higher than previous research reports which revealed prevalence of $35 \%$ for subtle thyroid dysfunction and $1-2 \%$ for overt thyroid disease among HIV infected individuals. ${ }^{7}$ The higher prevalence observed in this study may be linked to nutritional and geographic differences of the study populations. $^{22,23}$

Furthermore, the prevalence of subclinical hypothyroidism in this study was higher among the HIV-positive HAART treated patients than HIV-positive HAART naïve patients. Similar find- ings were observed by previous reports. ${ }^{24-26}$ In contrast however, Collazos et al., reported a lower prevalence in a Spanish population of 202 HIV patients. ${ }^{27}$

The prevalence of overt hypothyroidism was similar among HIV-positive patients on HAART and HIV-positive HAART naïve patients. Similar observations were also reported by some researchers. ${ }^{9,26,28,29}$

None of the cases of hypothyroidism among the HIV positive patients had elevated levels of TPO-Ab, suggesting that the aetiology may not be of autoimmune origin. This finding is consistent with other findings that showed that HIV-infected patients with hypothyroidism rarely express TPO-Ab. ${ }^{7,24,30}$

Table 3. Serum $\mathrm{fT}_{3}, \mathrm{fT}_{4}$, TSH and TPO-Ab of study Participants by group.

\begin{tabular}{lcccc} 
Parameter* & Group I & Group II & Group III & P value \\
$\begin{array}{l}\mathrm{fT}_{3} \\
(\mathrm{pmol} / \mathrm{L})\end{array}$ & $4.55 \pm 0.90$ & $3.84 \pm 0.74$ & $5.14 \pm 0.77$ & 0.0000 \\
$\mathrm{fT}_{4}$ & $13.24 \pm 4.55$ & $13.30 \pm 1.85$ & $15.42 \pm 1.89$ & 0.0000 \\
$(\mathrm{pmol} / \mathrm{L})$ & & & & \\
\hline $\mathrm{TSH}$ & 2.32 & 2.05 & 1.29 & 0.0001 \\
$(\mu \mathrm{IU} / \mathrm{mL})$ & $(0.06-22.69)$ & $(0.71-13.22)$ & $0.05-9.08)$ & \\
$\mathrm{TPO}-\mathrm{AbNN}$ & 7.44 & 5.62 & 11.04 & 0.0001 \\
$(\mathrm{IU} / \mathrm{mL})$ & $(5.00-50.00)$ & $(5.00-21.78)$ & $(6.40-87.27)$ & \\
\hline
\end{tabular}

*Results of serum $\mathrm{fT}_{3}$ and $\mathrm{fT}_{4}$ are presented as mean \pm SD while the results of TSH and TPO-Ab are presented as median with range in brackets.

Table 4. Prevalence and Patterns of thyroid dysfunction among study participants.

\begin{tabular}{|c|c|c|c|c|}
\hline Category & $\begin{array}{l}\text { Group I } \\
\text { N (\%) }\end{array}$ & $\begin{array}{c}\text { Group II } \\
\text { N (\%) }\end{array}$ & $\begin{array}{c}\text { Group III } \\
\text { N (\%) }\end{array}$ & $\begin{array}{l}\text { Total } \\
\text { N (\%) }\end{array}$ \\
\hline roid & $31(44.3)$ & $40(57.1)$ & $68(97.1)$ & $139(66.2)$ \\
\hline Isolated low fT 4 & $20(28.6)$ & $11(15.7)$ & $0(0.0)$ & $31(14.8)$ \\
\hline Subclinical hypothyroidism & $12(17.1)$ & $9(12.9)$ & $1(1.4)$ & $22(10.5)$ \\
\hline Overt hypothyroidism & $2(2.9)$ & $2(2.9)$ & $0(0.0)$ & $4(1.9)$ \\
\hline Subclinical hyperthyroidism & $2(2.9)$ & $0(0.0)$ & $1(1.4)$ & $3(1.4)$ \\
\hline Elevated $\mathrm{fT}_{3}$ & $1(1.4)$ & $0(0.0)$ & $0(0.0)$ & $1(0.5)$ \\
\hline Low fT $\mathrm{f}_{3}$ and $\mathrm{fT}_{4}$ & $2(2.9)$ & $8(11.4)$ & $0(0.0)$ & $10(4.8)$ \\
\hline Total dysfunction & $40(55.7)$ & $30(42.9)$ & $2(2.8)$ & $71(33.8)$ \\
\hline *TPO-Ab & $1(1.4)$ & $0(0.0)$ & $4(5.7)$ & $5(2.4)$ \\
\hline
\end{tabular}

*TPO-Ab was elevated in five of the study participants; one among group I participants and four among group III participants.

Table 5. Serum $\mathrm{fT}_{3}, \mathrm{fT}_{4}, \mathrm{TSH}$ and TPO-Ab of group I study participants by HAART regimen.

\begin{tabular}{lccc}
\hline $\begin{array}{l}\text { Parameter* } \\
\mathrm{fT}_{3}\end{array}$ & Group la & Group Ib & P value \\
$(\mathrm{pmol} / \mathrm{L})$ & $4.64 \pm 0.72$ & $4.46 \pm 1.06$ & 1.000 \\
$\mathrm{fT}_{4}$ & $12.14 \pm 2.21$ & $14.42 \pm 5.95$ & 0.010 \\
$(\mathrm{pmol} / \mathrm{L})$ & 2.47 & 1.82 & 0.001 \\
$\mathrm{TSH}$ & $(0.58-22.69)$ & $(0.06-9.63)$ & \\
$(\mu \mathrm{IU} / \mathrm{mL})$ & 6.34 & 6.29 & 0.9 \\
$\mathrm{TPO}-\mathrm{Ab}$ & $(5.00-26.15)$ & $(5.00-50.00)$ & \\
$(\mathrm{IU} / \mathrm{mL})$ & &
\end{tabular}

*Results of serum fT3 and fT4 are presented as mean \pm SD while the results of TSH and TPO-Ab are presented as median with range in brackets. 
Out of the five participants that had elevated TPO-Ab, four (4) of them were HIV negative control study participants with their $\mathrm{ft}_{3}$, $\mathrm{ft}_{4}$ and TSH within the reference intervals. Studies have shown that elevated levels of TPO-Ab may be detected in about $10 \%$ to $15 \%$ of healthy population with normal thyroid function. ${ }^{31,32}$ One of the female participants with subclinical hyperthyroidism had elevated TPO-Ab levels. Subclinical hyperthyroidism may predate overt/clinical hyperthyroidism. Recently, thyroid dysfunction has been described as a component of immune reconstitution syndrome. Autoimmune thyroid disorder has been reported to occur in association with initiation of potent ART and improved immune function. ${ }^{33}$

Several research works have reported similar findings (as observed in this study) suggesting a higher prevalence of thyroid abnormalities in HIV patients especially with use of HAART and most of the abnormalities were not autoimmune mediated. $6,7,10-$ $12,16,24-26,29-32$

In conclusion therefore, this study has established that thyroid dysfunction is common among HIV-positive patients than HIVnegative controls with subclinical hypothyroidism being the commonest abnormality. The study also observed that thyroid disorders in HIV patients were mostly not autoimmune mediated. However, autoimmunity appears to play a little role in the development of hyperthyroidism in HIV/AIDS patients.

\section{References}

1. Hymes KB, Cheung T, Greene JB, et al. Kaposi Sarcoma in Homosexual Men: A Report of Eight Cases. Lancet 1981;2:598-600.

2. United Nations Programme on HIV/AIDS (UNAIDS) Fact sheet- Latest statistics on the status of the AIDS epidemic. 2016. Accessed July 2017.

3. Federal Republic of Nigeria. National Agency for Control of AIDS (NACA), Global AIDS Response Country Progress Report (GARPR), 2014.

4. Federal Republic of Nigeria. National Agency for Control of AIDS (NACA), Global AIDS Response Country Progress Report (GARPR) 2015.

5. Grinspoon SK. Endocrinology of HIV and AIDS In: Melmed S, Polonsky KS, Larsen PR, Kronenberg HM, Editors. Williams textbook of Endocrinology. 12th edition. Philadelphia: Saunders Elsevier; 2011. pp 1675-1679.

6. Abbiyesuku FM, Osuji KC, Kuti MO, Atiba MS. Thyroid Function Tests in Nigerian HIV sero-positive patients on HAART. Int J Med Clin Res 2014;5:277-81.

7. Hoffmann CJ, Brown TT. Thyroid function abnormalities in HIV infected Patients. Clin Infect Dis 2007;45:488-94.

8. Thaimuta ZL, Sekadde-Kigondu C, Makawiti DW. Thyroid Function among HIV/AIDS Patients on Highly Active AntiRetroviral Therapy. East Afr Med J 2010;87:474-80.

9. Beltran S, Lescure FX, Desailloud R, et al. Increased Prevalence of Hypothyroidism among Human Immunodeficiency Virus-Infected Patients: A Need for Screening. Clin Infect Dis 2003;37:579-83.

10. Jain G, Devpura G, Gupta BS. Abnormalities in the Thyroid Function Tests as Surrogate Marker of Advancing HIV Infection in Infected Adults. JAPI 2009;57:508-10.

11. Grappin M, Piroth L, Verges B, et al. Increased Prevalence of Subclinical Hypothyroidism in HIV Patients Treated with Highly Active Antiretroviral Therapy. AIDS 2000;14:1070-2.

12. Goddard GZ, Shoenfeld Y. HIV and autoimmunity.
Autoimmun Rev 2002;1:329-37.

13. Longo D, Fauci A, Kasper D, Hauser S, James J, Loscalzo J. Harrison's Principles of Internal Medicine. 18th ed. Massachusetts: McGraw-Hill; 2011.

14. Keffer JH. Pre-analytical considerations in testing thyroid function. Clin Chem 1996;42:125-35.

15. Stata Corp. Stata Version 13, College Station Texas, USA. 2014.

16. Sellmeyer DE, Grunfeld C. Endocrine and Metabolic Disturbances in Human Immunodeficiency Virus Infection and the Acquired Immune Deficiency Syndrome. Endocrinol Rev 1996; 17:518-27.

17. Nwozor CM, Nwankwo J. CD4 Cell Count of HIV-Positive Patients in Awka, South East Nigeria. Greener J Epidemiol Public Health 2013;1:10-5.

18. Laah JG, Ayiwulu E. Socio-Demographic Characteristics of Patients Diagnosed with HIV/AIDS in Nasarawa-Eggon. Asian J Med Sci 2010;2:114-20.

19. Gilbert PB, McKeague IW, Eisen G, et al. Comparison of HIV1 and HIV-2 infectivity from a Prospective Cohort Study in Senegal. Stat Med 2003;22:573-93.

20. Sujit KT, Ritesh KA, Anoj KB. Endocrine alterations in HIVinfected patients. Ind J Endocrinol Metab 2015; 19:143-47.

21. Iliyasu T, Arotiba JT, Babashani M. Socio-demographic characteristics and risk factors among HIV/AIDS patients in Kano, Northern Nigeria. Niger J Med 2005;14:459-60.

22. Nimmy NJ, Aneesh PM, Narmadha MP, Udupi RH, Binu KM. A survey on the prevalence of Thyroid Disorder Induced by Demography and Food Habits in South Indian Population. Ind J Pharm Pract 2012;5:49-52.

23. Fisher DA. Physiological Variations in Thyroid Hormones: Physiological and Pathological considerations. Am Assoc Clin Chem J 1996;42:135-9.

24. Calza L, Manfredi R, Chiodo F. Subclinical hypothyroidism in HIV infected patients receiving highly active antiretroviral therapy. J Acquir Immune Defic Syndr 2002;31:361-3.

25. Brocckmeyer N, Kreuter A, Bader A, et al. Prevalence of endocrine dysfunction in HIV-infected men. Horm Res 2000;54:294-5.

26. Sujit KT, Ritesh KA, Anoj KB. Endocrine alterations in HIVinfected patients. Indian J Endocrinol Metab 2015;19:143-7.

27. Collazos J, Ibarra S, Mayo J. Thyroid hormones in HIV-infected patients on highly active antiretroviral therapy era: evidence of an interaction between the thyroid axis and the immune system. AIDS 2003;17:763-5.

28. Jain G, Devpura G, Gupta BS. Abnormalities in the Thyroid Function Tests as Surrogate Marker of Advancing HIV Infection in Infected Adults. JAPI 2009;57:508-10.

29. Madge S, Smith CJ, Lampe FC, et al. No association between HIV disease and its treatment and thyroid function. HIV Med 2006;8:22-7.

30. Beltran S, Lescure FX, El-Esper I, Schmitt JL, Desailloud R. Subclinical hypothyroidism in HIV-infected patients is not an autoimmune disease. Horm Res 2006;66:21-6.

31. Winter WE, Schatz D, Bertholf RL. Thyroid Disorders. In: Tietz Fundamentals of Clinical Chemistry. 7th ed. Elsevier: 2015. pp 806-823.

32. Saravan P, Dayan CM. Assessment of thyroid function disease: Thyroid autoantibodies. Endocrin Metab Clin 2001;30:315-37.

33. Chen F, Day SL, Metcalfe RA, et al. Characteristics of autoimmune thyroid disease occurring as a late complication of immune reconstitution in patients with advanced human immunodeficiency virus disease. Medicine 2005;84:98-106. 